\title{
What Went Wrong in Managing SARS-Cov-2
}

\section{Quirino Piacevoli* ${ }^{1 *}$ and Ahsina Jahan ${ }^{2}$}

${ }^{1}$ Professor, President of the World Society of Intravenous Anesthesia, Member of Many Scientific Boards and Committees of Different Countries, Member of the Board of the Federation European Des Medicine, Bruxelles, Belgium

${ }^{2}$ MH Samorita Hospital and Medical College Dhaka Banglades

*Corresponding Author: Quirino Piacevoli, Professor, President of the World Society of Intravenous Anesthesia, Member of many Scientific Boards and Committees of Different Countries, Member of the Board of the Federation European Des Medicine, Bruxelles, Belgium.

In recent months, since the beginning of the pandemic, we have witnessed numerous debates on this issue, with very often divergent if not conflicting conclusions, with opinions with scientific content and many others with a naïve flavor. All this pseudo-intellectual-scientific cacophony one thing made us understand, that the pandemic has made us change our way of life. Many things will never be the same again.

And while we are living a liberating moment from this nightmare in some Western countries, we are unaware that the virus continues to wipe out thousands of lives in countries close to us such as Russia, Great Britain, not to mention India, Pakistan, Bangla Desh, Malaysia, the Philippines, Indonesia, Japan. I would like to recall what the Secretary of the United Nations, Antonio Guterrez, said recently in this regard during the G20 Conference in Rome on the "Global Health Summit": Nobody can be considered safe until everyone is safe. Strong and clear message that makes us understand how this is still in progress and whose developments are completely unpredictable. Today the most constructive and enlightened debate in the world focuses on how it could have come to a point where humanity was endangered and the global economy undermined by creating huge pockets of poverty and dramatically increasing diversity. All this has led groups of independent scientists to wonder what mistakes have been made and if all this could have been avoided and finally how to prepare for the future so that this drama does not repeat itself. The first conclusion was that this disaster was entirely foreseeable.
Received: July 05, 2021

Published: August 01, 2021

(C) All rights are reserved by Quirino

Piacevoli and Ahsina Jahan.
Furthermore, it is stressed by many that the world needs a new international system for preparing and responding to pandemics, and it needs a faster one, to prevent future epidemics of infectious diseases from becoming catastrophic pandemics. Another evidence was the total absence of global political leadership.

The initial outbreak became a pandemic as a result of gaps and failures in every critical moment of COVID-19 preparedness and response.

Years of alarms of an inevitable pandemic threat have not been addressed and there have been inadequate funding and inadequate preparedness stress tests, despite the increasing rate at which zoonotic diseases are emerging. Precious time has been lost.

Too many countries have adopted a "wait and see" approach rather than an aggressive containment strategy that could have prevented the global pandemic. Countries with delayed responses have also been characterized by lack of coordination, inconsistent or non-existent strategies, and devaluation of science in guiding decision making.

Unfortunately, WHO member states had underpowered the agency to carry out the work required and at the same time some had even begun a campaign of discredit.

International funding was too little, too late. 
The fact that at least 18,000 health workers have died of COVID-19 in the first year of the pandemic underlines the need for countries to do much more to support and protect them.

The country's wealth did not prove to be a predictor of success.

The devastating reality of the COVID-19 pandemic has shown how an infectious disease can sweep the globe in weeks and, within months, delay sustainable development for years. The data, despite their lack of accuracy, give us knowledge of what happened:

178 million people have been confirmed infected and more than 3.8 million have died in 223 countries, territories and areas (as of April 28, 2021); • at least 18,000 health workers died from COVID-19 during the first year of the pandemic; $\bullet \$ 10$ trillion of production is projected to be lost by the end of 2021 and $\$ 22$ trillion in 2020-2025 - the deepest shock to the global economy since World War II and the largest simultaneous contraction of national economies from the Great Depression of 1930-1932; • At its peak in $2020,90 \%$ of schoolchildren were unable to attend school; $\bullet 10$ million more girls are at risk of early marriage due to the pandemic; - support services for gender-based violence have seen a fivefold increase in demand; • 115-125 million people have been pushed into conditions of extreme poverty. There are 5.7 billion people aged 16 and over in the world. Everyone needs access to safe and effective COVID-19 vaccines. This is not an aspiration for tomorrow, it is urgent now. "... The panel of scientific experts of the independent panel notes that the high risk of serious health crises is largely underestimated and that the preparedness and responsiveness of the world is woefully insufficient, as has sadly been found. Access to food, understanding where housing is, understanding medical information in a way that's makes sense to you is super important. So, it really is about organizing the world's information and making it useful and accessible. So, when we think about things like covid -19 for example, which I'm sure we'll get into, we have had 400 billion views of our covid information page on you tube, so that reaches wide audiences. There is increased attention driven by digital capabilities to be able to reach people where they are in their homes as we saw happen during the pandemic, and to connect them to a broader range of resources to help improve their health. Not just scheduling a visit with a doctor but figuring out if they're feeling isolated and mood issues or behavioral health needs could be met, figuring out if there are other social service needs, food insecurity, housing insecurity, and helping to connect that.
Pandemic preparedness planning is a key function of governments and the international system and must be supervised at the highest level. It is not the responsibility of the health sector alone.

It is essential to recognize one's own cognitive preconceptions

At the beginning of the spread of the virus, the Covid-19 epidemic in Italy was not considered a health emergency. The first warning signs were greeted with skepticism by both public opinion and many politicians, even though many scientists had claimed for weeks that there was a risk of catastrophe, thus creating a dangerous confirmation bias in public opinion, namely the tendency to focus on information that reinforces our initial opinion and assumptions.

The second lesson to be drawn from the Italian experience concerns the importance of adopting a systematic approach and the dangers of partial solutions. The latter have led, for example, to an increase in mortality not only in full Covid 19 included, but also for other diseases that have been neglected due to the pandemic.

Another effect, the effects of which will be felt for months, is that of having had to postpone hundreds of thousands of non-urgent interventions, with heavy organizational repercussions and on the health of citizens.

Modern medicine is rife with examples of double-edged swords. Many of which took years to reveal both edges. For example, rare is the medication that does not have unpleasant, even lethal side effects. Some predicted, others unanticipated, a few even beneficial. The human body also is an example of a seemingly contradictory double-edged biologic process: inflammation. On one hand, inflammation is a normal physiologic process essential to the body's ability to heal itself. On the other hand, growing evidence shows that inflammation may be the underlying trigger that sets a daunting array of disease processes in motion. While these factors have varying mechanisms by which they produce pathology, the common pathway to many diseases appears to be inflammation.

I love to hear the word homeostasis, because it's one of those terms that I think we don't actually... we're not familiar enough with it. But it's a very simple concept, which is that there's checks and balances to everything. And what we really need to try to do inside and out, is to keep that balance actually going so that we are kind of in that Goldilocks zone of life where things just kind of work 
out. If you stress too much on one side or the other, you're out of balance and therefore out of homeostasis. As I said, this has been an unimaginable year for all of us.

The recent studies that have discovered that Covid 19 is a disease that can have important consequences deserve a chapter in itself.

When we talk about "post-Covid syndrome" we refer to the persistence of more or less debilitating symptoms after the acute phase of the disease and the negativization of virological tests. 30$40 \%$ of positive Covid patients have symptoms and sequelae for many months after recovery. In addition to fatigue, breathing difficulties, coughs, heart and memory problems, new symptoms may also develop, never seen before the disease, such as emotional lability, mood disorders, anxiety and insomnia, dermatitis and many others. The virus persists for a long time in the stool, even if it is no longer detected by nasal swabs, and until the intestinal bacterial balance is restored, you may be subject to lack of appetite, weight loss and a sense of exhaustion. It is also important to manage the mental disorders of these patients, many of whom have a posttraumatic stress disorder".

How to quantify all this in economic terms and which organization will have to face such a complex and difficult situation is not yet known.

While the battle isn't over yet, it's clear that we will win and be better prepared for what may come in our future. COVID-19 has brought the world together against a common adversary. People in science and medicine, business, government and philanthropy have all embarked on a mission to save the world. Their response has been extraordinary, historic, and a lesson for the ages. The COVID vaccines were developed in just one year, a process that usually takes up to a decade. They push the boundaries of science without sacrificing safety. And the global response has produced benefits that can improve human health around the world.

Sometimes, science and faith can seem somewhat incompatible. Faith, you're believing in certain things. But with science, you want the evidence, you want the reason, the judgment. Just curious how do you think about science and faith and the inflection points, but also when something is truly novel, as the case with this coronavirus, there isn't a lot of evidence? How much do you have to rely on just your own faith, not necessarily religious faith, but just your system of beliefs? I use the word faith and I'm glad you said not necessarily religious faith. It really is a combination of instinct, good judgment, and calling back from experience. That, in some respects, is a non-religious faith issue.

The question at this point, which unfortunately we still do not know how to answer, is this: but will the great people of the world, beyond expressing good intentions, have learned their lesson?

Two British-American economists and political scientists, Daron Acemoglu and James Robinson, published in 2012, "Why Do Nations Fail?". Their thesis is as simple as it is brilliant.

Nations, and by extension any great public authority, fail when run by bad institutions. Because bad institutions lead to bad governance. And bad governance leads to bad results, hence more and more suffering.

\section{Volume 5 Issue 9 September 2021 (C) All rights are reserved by Quirino Piacevoli and} Ahsina Jahan. 